\title{
FBX045-MYCBP2 regulates mitotic cell fate by targeting FBXW7 for degradation
}

\author{
Kai T. Richter ${ }^{1,2} \cdot$ Yvonne T. Kschonsak $^{1}$ Barbara Vodicska ${ }^{1} \cdot$ Ingrid Hoffmann $^{1}$ \\ Received: 16 April 2019 / Revised: 14 June 2019 / Accepted: 18 June 2019 / Published online: 8 July 2019 \\ (c) The Author(s), under exclusive licence to ADMC Associazione Differenziamento e Morte Cellulare 2019
}

\begin{abstract}
Cell fate decision upon prolonged mitotic arrest induced by microtubule-targeting agents depends on the activity of the tumor suppressor and F-box protein FBXW7. FBXW7 promotes mitotic cell death and prevents premature escape from mitosis through mitotic slippage. Mitotic slippage is a process that can cause chemoresistance and tumor relapse. Therefore, understanding the mechanisms that regulate the balance between mitotic cell death and mitotic slippage is an important task. Here we report that FBXW7 protein levels markedly decline during extended mitotic arrest. FBXO45 binds to a conserved acidic N-terminal motif of FBXW7 specifically under a prolonged delay in mitosis, leading to ubiquitylation and subsequent proteasomal degradation of FBXW7 by the FBXO45-MYCBP2 E3 ubiquitin ligase. Moreover, we find that FBXO45MYCBP2 counteracts FBXW7 in that it promotes mitotic slippage and prevents cell death in mitosis. Targeting this interaction represents a promising strategy to prevent chemotherapy resistance.
\end{abstract}

\section{Introduction}

The attachment of a single ubiquitin molecule or a polyubiquitin chain to a eukaryotic protein is an essential signaling event that can profoundly affect the fate of the target protein. For example, the ubiquitin-proteasome system controls protein degradation in a broad array of cellular processes [1]. Cancer cells often contain mutations targeting ubiquitin-mediated proteolysis that lead to tumorigenesis. FBXW7, an F-box protein and substrate receptor for the SCF (SKP1-CUL1-F-box protein) E3 ubiquitin ligase

These authors contributed equally: Yvonne T. Kschonsak, Barbara Vodicska

\section{Edited by V. D'Angiolella}

Supplementary information The online version of this article (https:// doi.org/10.1038/s41418-019-0385-7) contains supplementary material, which is available to authorized users.

\section{Ingrid Hoffmann}

Ingrid.Hoffmann@dkfz.de

1 Cell Cycle Control and Carcinogenesis, F045, German Cancer Research Center, DKFZ, Im Neuenheimer Feld 242, 69120 Heidelberg, Germany

2 Faculty of Biosciences, Heidelberg University, 69120 Heidelberg, Germany complex, acts as a tumor suppressor and is mutated or deleted in a variety of human cancers [2]. FBXW7 exerts its antitumor activity through destruction of key oncoproteins, including JUN [3, 4], MYC [5, 6], Cyclin E [7-9], and Notch1 [10, 11].

The abundance of F-box proteins including FBXW7 is controlled by ubiquitylation and degradation in an autocatalytic reaction within the SCF complex [12]. FBXW7 autoubiquitylation can be regulated by Glomulin (GLMN), a protein that binds to RBX1 leading to inhibition of SCF activity, thereby increasing FBXW7 protein levels [13, 14]. The only ubiquitin ligase known to date involved in regulating FBXW7 levels in neurons is Parkin. However, this regulation has only been observed for the FBXW7 $\beta$ isoform [15]. It has also been shown that PLK2-kinase dependent phosphorylation of FBXW7 at S176 leads to its ubiquitinmediated degradation and stabilization of Cyclin E [16].

Accurate spindle function is crucial for a successful mitosis. Perturbation of microtubule dynamics leads to sustained activation of the spindle assembly checkpoint (SAC) [17]. The SAC delays exit from mitosis by preventing the anaphase-promoting complex/cyclosome-mediated proteolysis of Cyclin B1. Anticancer chemotherapeutics including vinca alkaloids or taxanes target microtubules and are successfully used in the clinics to treat multiple types of cancer. Antimicrotubule drugs cause an arrest or prolonged delay in mitosis followed by 
mitotic cell death. On the other hand, slow degradation of Cyclin B1 during a prolonged mitotic arrest can cause cells to prematurely exit from mitosis, a process called mitotic slippage [18]. During mitotic slippage, cells do not undergo proper chromosome segregation and cytokinesis. Most of the resulting tetraploid cells either undergo cell death after mitosis or arrest in interphase. However, depending on the p53 status of these cells, they may continue to proliferate as genomically unstable cells. This can lead to chemoresistance, thereby limiting the therapeutic use of antimicrotubule drugs $[19,20]$. FBXW7 is a known regulator of mitotic cell fate. Upon mitotic arrest, FBXW7 promotes mitotic cell death and prevents mitotic slippage [21, 22].

FBXO45 (FSN-1 in Caenorhabditis elegans; DFsn in Drosophila melanogaster) is an evolutionary conserved Fbox protein. FBXO45 is atypical in that it binds to SKP1 via its F-box motif, but recruits an alternate RING-finger protein known as MYCBP2, a member of the PHR (PAM/ Highwire/RPM-1) protein family and E3 ubiquitin ligase. MYCBP2 was shown to have important functions in developmental processes, such as axon termination and synapse formation, as well as axon degeneration (reviewed by $[23,24])$. FBXO45 contains a conserved F-box domain and a SPRY domain, which recruits substrates to the ubiquitin ligase complex [25] [26]. FBXO45-MYCBP2 has been linked to the proteasomal degradation of a few targets including the DLK-1 and p38 MAP kinase pathway [27] and the nicotinamide-nucleotide adenylyltransferase family member NMNAT [28].

Here we report the identification of the E3 ligase FBXO45-MYCBP2 as a regulator of FBXW7 abundance during prolonged mitotic arrest induced by spindle poisons. FBXO45 binds to a conserved acidic $\mathrm{N}$-terminal region of FBXW7. Depletion of FBXO45 leads to the stabilization of FBXW7 protein upon mitotic arrest. Ubiquitylation of FBXW7 by FBXO45-MYCBP2 induces its proteasomal degradation inducing an increase in mitotic slippage and prevention of mitotic cell death.

\section{Results}

\section{Prolonged mitotic arrest leads to reduced FBXW7 protein levels}

The SCF-FBXW7 complex acts as a key factor determining sensitivity to antimitotic drugs in cancer by inducing mitotic cell death and preventing mitotic slippage [29, 22, 21]. As mitotic slippage frequently occurs under prolonged mitotic arrest, it is conceivable that this could be induced by a decrease in FBXW7 protein levels. To address this, we analyzed protein levels of the ubiquitously expressed $\alpha$ isoform of FBXW7 in mitotic HeLa cells at different time points after induction of mitotic arrest. We observed a slow but gradual decrease in the amount of FBXW7 protein during prolonged mitotic arrest (Fig. 1a). The dynamics of this decrease was similar to the decay of two other regulators of mitotic cell fate, Cyclin B1 and MCL-1 [18, 30]. Moreover, the decay of FBXW7, Cyclin B1, and MCL-1 was prevented by the addition of the proteasomal inhibitor MG132 (Fig. 1b). We therefore anticipated that FBXW7 protein levels could be decreased in response to proteasomal protein degradation. To identify proteins that regulate SCFFBXW7 protein levels we made use of an unbiased screen where we aimed at identifying FBXW7 binding proteins. We expressed Flag-FBXW7 $\alpha$ in HEK-293T cells, FBXW7 $\alpha$ complexes were immunoprecipitated and subsequent mass spectrometrical analysis was performed. Among the identified peptides were sequences corresponding to FBXO45 and MYCBP2, along with SCF components and known substrates of FBXW7 including MYC, Notch $1 / 2$, and members of the mediator complex (Fig. 1c, Supplementary Table 1). Interestingly, FBXO45 and MYCBP2 have previously been identified in other screens for FBXW7 interacting proteins [31, 32]. They have also been described to form an SCF-like E3 ubiquitin ligase complex [33]. We therefore analyzed whether FBXO45MYCBP2 is the ubiquitin ligase that regulates FBXW7 protein levels under prolonged mitotic arrest.

\section{The FBX045-MYCBP2 complex binds to a conserved $\mathrm{N}$-terminal motif in FBXW7a}

First, we checked whether FBXO45 and FBXW7 $\alpha$ bind to each other and found that Flag-FBXO45 was able to coimmunoprecipitate endogenous FBXW7 $\alpha$ (Fig. 2a) and vice versa Flag-FBXW7 $\alpha$ co-immunoprecipitated endogenous FBXO45 (Fig. 2b). To confirm the specificity of the binding between FBXW7 $\alpha$ and FBXO45, several other F-box and DCAF substrate receptors were expressed and immunoprecipitated. No interaction was detected between FBXO45/ FBXW7 $\alpha$ and the control proteins suggesting that the binding of FBXO45 and FBXW7 $\alpha$ was specific (Fig. 2a, b). FBXW7 occurs in three isoforms, FBXW7 $\alpha$, FBXW7 $\beta$, and FBXW7 $\gamma$, that differ in subcellular localization and their N-terminal domain. FBXW7 $\alpha$ is thought to perform most FBXW7 functions [2]. To identify the binding site of FBXO45 within FBXW7, we generated different FBXW7 $\alpha$ truncated versions and found that aa106-126 in the N-terminal domain of FBXW7 $\alpha$ was required for FBXO45 binding (Supplementary Fig. 1A-D). Coimmunoprecipitation experiments using full-length FlagFBXW7 $\alpha$ or a Flag-FBXW7 $\alpha \Delta 106-126$ mutant showed that FBXW7 $\alpha \Delta 106-126$ failed to bind FBXO45 and MYCBP2 (Fig. 2c). This could be confirmed by the fact that FBXO45 only interacted with FBXW7 $\alpha$ but not with the 
A
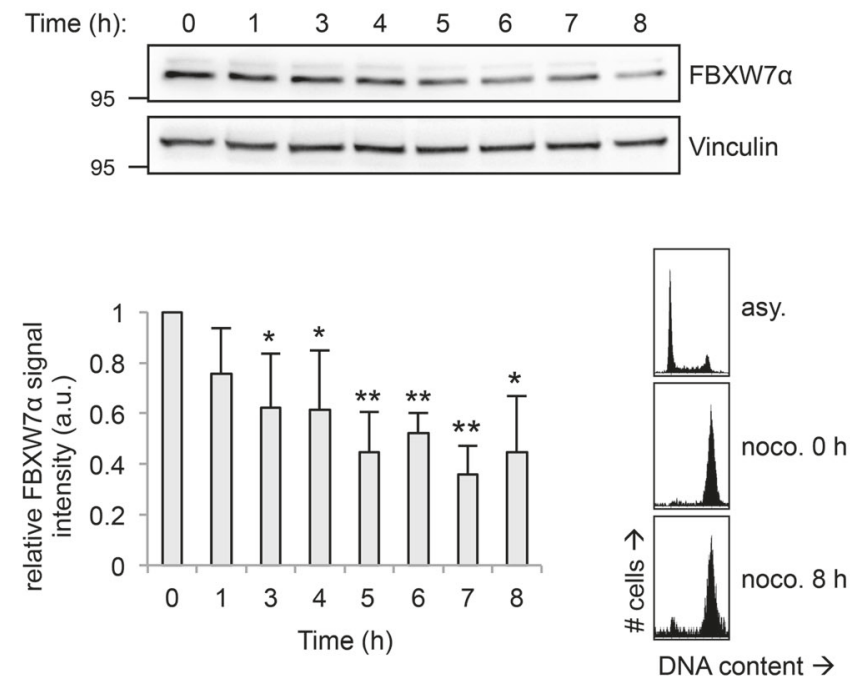

C

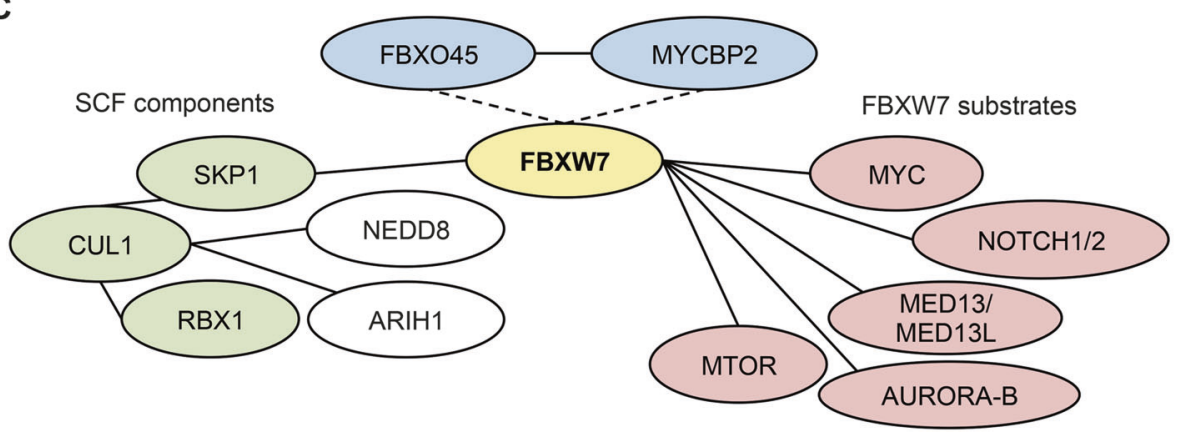

Fig. 1 FBXW7 protein levels are reduced under prolonged mitotic arrest. a FBXW7 $\alpha$ protein levels decrease during prolonged mitotic arrest. HeLa cells were treated with $250 \mathrm{ng} / \mathrm{ml}$ nocodazole for $2 \mathrm{~h}$. Mitotic cells were collected by mitotic shake-off (time point 0 ) and further incubated with $250 \mathrm{ng} / \mathrm{ml}$ nocodazole. The cells were harvested at different time points by a mitotic shake-off. (Top) Cell extracts were prepared and analyzed by western blotting. (Bottom, left) Relative FBXW7 $\alpha$ signal intensities were quantified. Average signal intensities and standard deviations from $n=4$ experiments were calculated. Statistical significance (difference to time point 0 ) was analyzed by a two-tailed, unpaired $t$-test with unequal variance. $* p<0.05$; ** $p<$ 0.01. (Bottom, right) Mitotic arrest was confirmed for two time points $(0 \mathrm{~h}$ and $8 \mathrm{~h}$ ) by FACS analysis. Asynchronous (asy.) cells served as a control. b Decrease in FBXW7 $\alpha$ protein levels during prolonged mitotic arrest depends on proteasomal activity. (Top) HeLa cells were treated with $250 \mathrm{ng} / \mathrm{ml}$ nocodazole for $2 \mathrm{~h}$. Mitotic cells were collected

other two isoforms, FBXW7 $\beta$ or FBXW7 $\gamma$ (Supplementary Fig. 1E), that lack the FBXW7 $\alpha$-specific N-terminal domain [34] again suggesting FBXW7 $\alpha$ specifically binds FBXO45. Interestingly, the N-terminal stretch within the FBXW7 $\alpha$ isoform (aa106-126) harbors conserved acidic amino acid residues as a potential FBXO45 interaction domain (Fig. 2d). On the other hand, we identified the
B
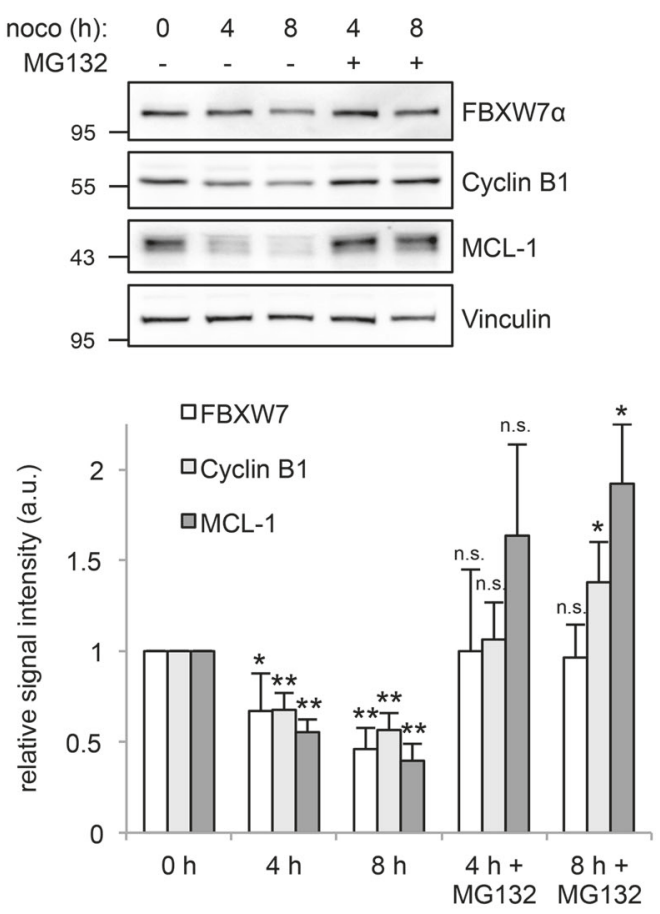

by mitotic shake-off (time point 0 ) and further incubated with $250 \mathrm{ng} /$ $\mathrm{ml}$ nocodazole. MG132 was added in order to inhibit the proteasome. Cells were harvested at different time points by a mitotic shake-off. Cell extracts were prepared and analyzed by western blotting. (Bottom) Relative FBXW7 $\alpha$, Cyclin B1, and MCL-1 signal intensities were quantified. Average signal intensities and standard deviations from $n=4$ experiments were calculated. Statistical significance (difference to time point 0 ) was analyzed by a two-tailed, unpaired $t$-test with unequal variance. $* p<0.05 ; * * p<0.01 ;$ n.s. not significant. c Network of known and putative FBXW7 interaction partners. Immunoprecipitation of Flag-FBXW7 $\alpha$ from HEK-293T cells treated with the proteasomal inhibitor MG132 for $4 \mathrm{~h}$ and subsequent mass spectrometry analysis identified several known SCF components and the SCF regulators NEDD8 and ARIH1 as well as FBXW7 substrates. Moreover, FBXO45 and MYCBP2 were identified as FBXW7 interaction partners and could act as putative FBXW7 regulators

central domain of MYCBP2 (aa1951-2950) to be responsible for FBXW7 $\alpha$ binding (Supplementary Fig. 1F-G). As this domain also contains the FBXO45 interaction site of MYCBP2, we hypothesized that FBXO45 could be the direct interaction partner of FBXW7 $\alpha$ within the FBXO45MYCBP2 complex. Analysis of binding between purified MBP-tagged N-terminal domain of FBXW7 $\alpha$ (MBP- 
A

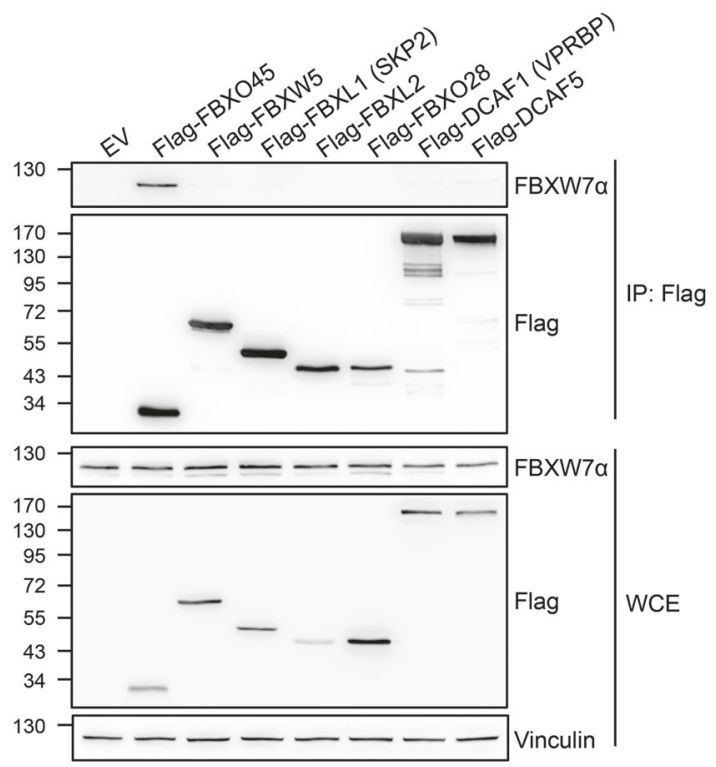

C

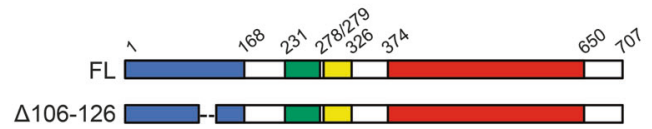

$\square$ N-terminal domain of FBXW7a $\square$ Dimerization domain

$\square$ F-box domain $\square$ WD40 repeat domain

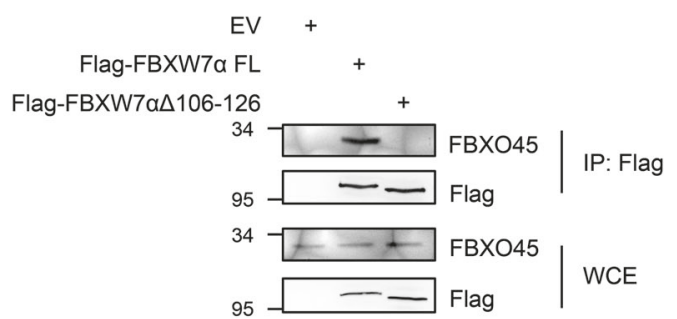

Flag-FBXW7a FL Flag-FBXW7 $\alpha \Delta 106-126$ Myc-MYCBP2

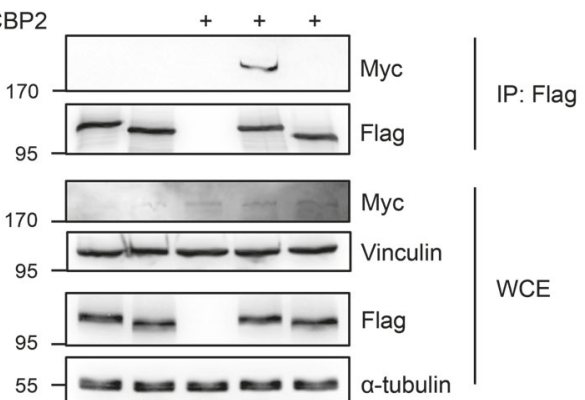

D

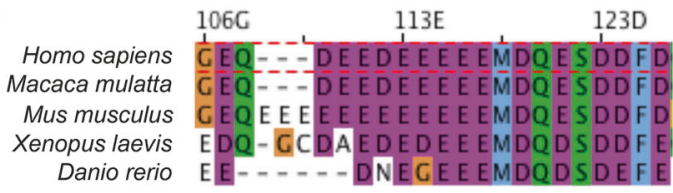

FBXW7 $\alpha-\mathrm{N} 167)$ and in vitro translated $\left[{ }^{35} \mathrm{~S}\right]-\mathrm{FBXO} 45$ or $\left[{ }^{35}\right.$ S]-MYCBP2(1951-2950) showed that FBXW7 $\alpha$ directly binds to FBXO45 but not to MYCBP2 (Fig. 2e).

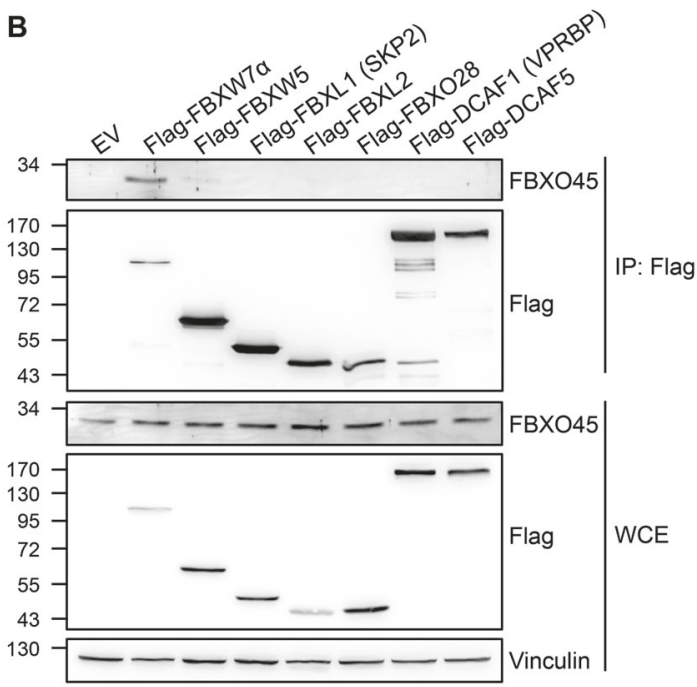

E $\underset{\text { MBP }}{\stackrel{\text { Input }}{\text { PD: MBP }}} \stackrel{+}{+}$

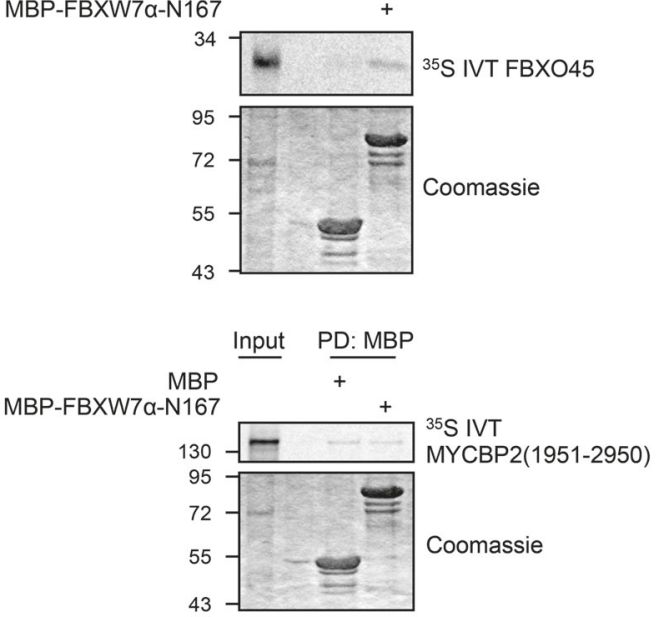

$\mathbf{F}$

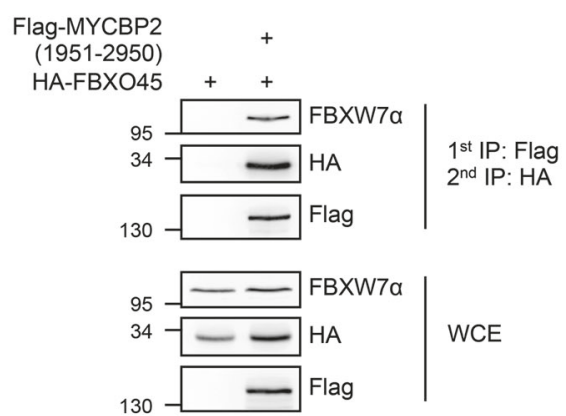

Furthermore, using sequential co-immunoprecipitation experiments we showed that FBXW7 $\alpha$ exists in a complex with FBXO45 and MYCBP2 (Fig. 2f). 
Fig. 2 FBXO45-MYCBP2 binds to a conserved N-terminal motif of FBXW7 $\alpha$ a, b FBXO45 and FBXW7 $\alpha$ specifically interact in reciprocal immunoprecipitations. Several Flag-tagged F-box and DCAF proteins were overexpressed in HEK-293T cells for $24 \mathrm{~h}$. Cell extracts were used for an immunoprecipitation directed against the Flag tag. c (Top) Schematic representation of $\Delta 106-126$ deletion in FBXW7 $\alpha$ used in immunoprecipitation experiments. Positions of $\mathrm{N}$-terminal domain (blue), dimerization domain (green), F-box domain (yellow), and WD40 domain (red) are indicated. (Bottom) FBXO45 and MYCBP2 interact with the N-terminal domain of FBXW7 $\alpha$. FlagFBXW7 $\alpha$ FL or Flag-FBXW7 $\alpha \Delta 106-126$ were overexpressed in HEK-293T cells for $24 \mathrm{~h}$. Cell extracts were used for $\alpha$-Flag immunoprecipitations. d Sequence alignment of amino acid residues 106-126 from human FBXW7 $\alpha$ with homologs from Macaca mulatta, Mus musculus, Xenopus laevis, and Danio rerio. e Either MBP alone or MBP-FBXW7 $\alpha-\mathrm{N} 167$ were incubated with in vitro translated and $\left[{ }^{35}\right.$ S]-methionine containing FBXO45 or MYCBP2(1951-2950). MBP was pulled down with amylose beads. Pull-down samples were analyzed by SDS-PAGE and Colloidal Coomassie staining. In vitro translated proteins were detected by autoradiography. f FBXW7 $\alpha$ forms a complex with MYCBP2 and FBXO45. Flag-MYCBP2(19512950) and HA-FBXO45 were co-expressed in HEK-293T cells for 24 h. Cell extracts were used for an immunoprecipitation with $\alpha$-Flag agarose beads. Immunoprecipitated proteins were eluted by competition with Flag peptide. Eluates were used for a second immunoprecipitation directed against the HA tag. Immunoprecipitates obtained after sequential immunoprecipitation were analyzed by western blotting

For some but not all F-box proteins it has been demonstrated that phosphorylation of their specific substrates is required for binding [35]. We have previously shown that phosphorylation of FBXW7 by PLK2 leads to destabilization of the F-box protein [16]. However, as shown in Supplementary Fig. 1H, inhibition of PLK2 by the small molecule inhibitor BI2536 that targets both PLK1 and PLK2 kinases did not impair the binding between FBXO45 and FBXW7. Moreover, overexpression of GFP-PLK2 did not promote the interaction (Supplementary Fig. 1I). Our data therefore suggest that the FBXW7 $\alpha$-FBXO45 interaction is independent of phosphorylation by PLK2.

Together, these results show that the FBXO45-MYCBP2 complex interacts with a conserved acidic stretch within the $\mathrm{N}$-terminal domain of FBXW7 $\alpha$.

\section{FBX045-MYCBP2 targets FBXW7a for degradation specifically during mitotic arrest}

As FBXW7 $\alpha$ is predominantly found in the nucleus [36], whereas FBXO45 and MYCBP2 are cytosolic proteins [25, 37] (Fig. 3a), a possible interaction between these proteins may occur in mitosis upon nuclear envelope breakdown, when the contents of the cell nucleus are released into the cytoplasm. As FBXO45 is likely to be the substrate binding factor, we analyzed the interaction between Flag-FBXO45 and endogenous FBXW7 $\alpha$ in asynchronous and mitotic HeLa cells. We specifically prepared the cell extracts for the experiment shown in Fig. $3 \mathrm{~b}$ under conditions where the nucleus remains intact in asynchronous cells thus preventing the interaction between FBXO45 (cytoplasmic) and FBXW7 $\alpha$ (nuclear). Interestingly, FBXW7 $\alpha$ was specifically found in coimmunoprecipitation with Flag-FBXO45 in mitotic cells where the nuclear envelope is disassembled (Fig. 3b).

Furthermore, we noticed an increase in FBXW7 $\alpha$ protein levels upon siRNA-mediated downregulation of FBXO45. This effect could only be observed in cells under a prolonged mitotic arrest but not in cells passing through an unperturbed mitosis. In addition, the effect was not observed in asynchronous cells (Fig. 4a and Supplementary Fig. 2A, B). On the other hand, FBXW7 downregulation had no effect on FBXO45 protein levels (Fig. 4a). To exclude off-target effects we used different FBXO45 and MYCBP2 siRNAs to reduce their expression in HeLa cells and confirmed that $\mathrm{FBXW} 7 \alpha$ protein levels were upregulated in cells that were FBXO45 or MYCBP2-depleted under prolonged mitotic arrest (Supplementary Fig. 2C). The effect could be confirmed in U2OS cells using nocodazole and in HeLa cells using different inhibitors that cause a mitotic arrest (Supplementary Fig. 2D-I). We also aimed to confirm the observed regulation of $\mathrm{FBXW7} \alpha$ protein levels by expression of a dominant-negative MYCBP2(1951-2950) fragment that binds FBXO45 and FBXW7 $\alpha$ but lacks the RING domain (Supplementary Fig. 1F, G). Upon ectopical expression of Flag-MYCBP2 (1951-2950) we found that FBXW7 $\alpha$ protein levels were specifically upregulated in mitotic cells after treatment with nocodazole (Fig. 4b). Taken together, FBXO45 binds FBXW7 $\alpha$ in mitotic cells and the FBXO45-MYCBP2 complex regulates $\mathrm{FBXW7} \alpha$ protein levels specifically during mitotic arrest.

\section{FBX045-MYCBP2 targets FBXW7a for ubiquitylation and degradation}

To find out whether the regulation of $\mathrm{FBXW7} \alpha$ by FBXO45-MYCBP2 is mediated by ubiquitylation we carried out in vivo ubiquitylation assays. We found that both overexpression of FBXO45 and MYCBP2 promote ubiquitylation of FBXW7 $\alpha$ (Fig. 5a). Deletion of the FBXO45 binding site in FBXW7 $\alpha$ reduced the ubiquitylation of FBXW7 $\alpha$ markedly in in vivo ubiquitylation assays using FBXW7 $\alpha \Delta$ 106-126 expression (Fig. 5b). To study the effect of FBXO45 on FBXW7 $\alpha$ protein stability, we depleted FBXO45 in nocodazole-treated cells and added cycloheximide to block translation. Cells were then harvested at different time points after cycloheximide addition. In FBXO45-depleted cells FBXW7 $\alpha$ was markedly stabilized (Fig. 5c) suggesting that FBXO45 promotes degradation of FBXW7 $\alpha$ upon mitotic arrest. In addition, Flag-FBXW7 $\alpha \Delta 106-126$ was stabilized in 
Fig. 3 FBXO45 and FBXW7 $\alpha$ interact during mitotic arrest. a $\mathrm{FBXW7} \alpha$ is a nuclear protein, whereas FBXO45 is localized in the cytoplasm. Cytoplasmic and nuclear extracts were prepared from HeLa cells and analyzed by western blotting. b FBXO45 and FBXW7 $\alpha$ interact

predominantly in mitosis. FlagFBXO45 was overexpressed in HeLa cells. Asynchronous or mitotic cells that had been treated with nocodazole for $17 \mathrm{~h}$ were harvested. Cytoplasmic extracts were used for an immunoprecipitation directed against the Flag tag
A

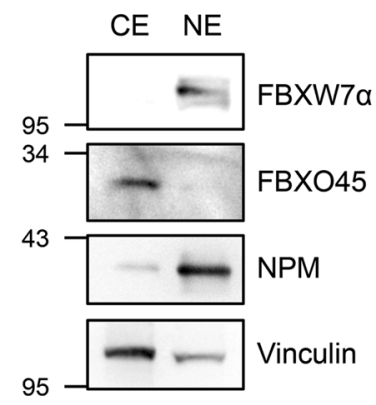

B

Flag-

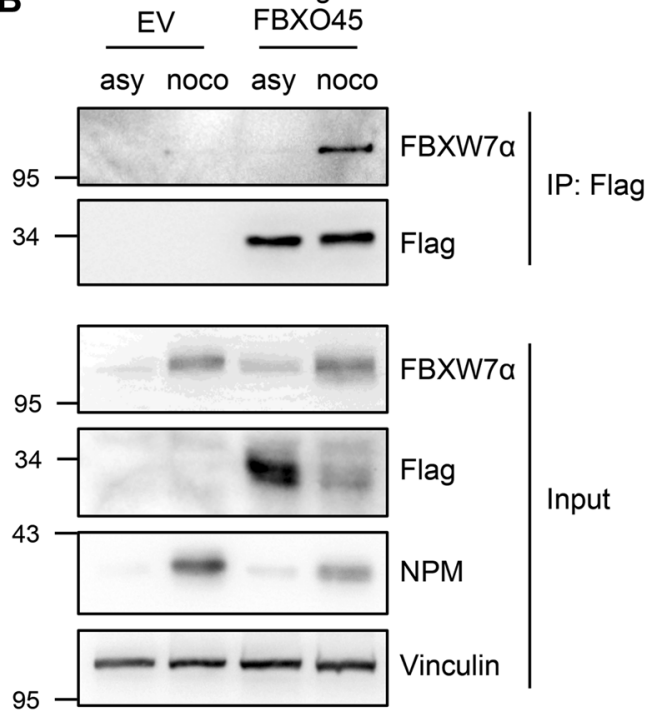

A

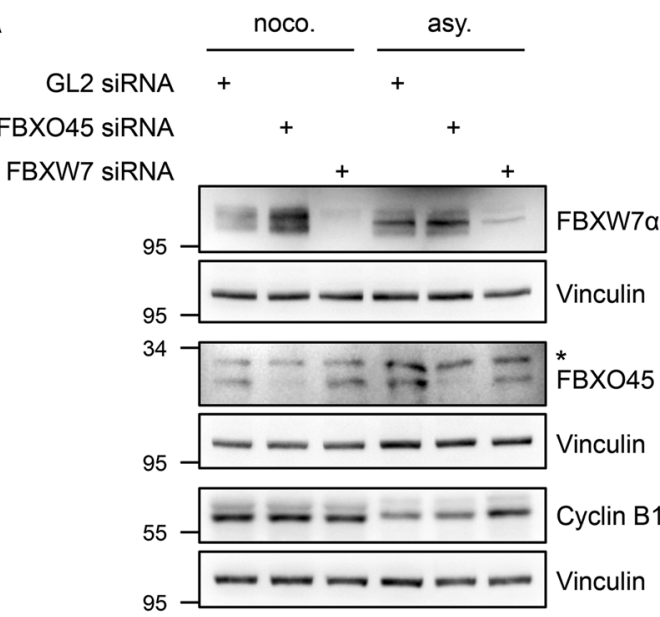

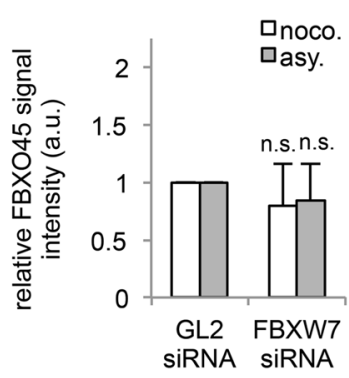

Fig. 4 FBXO45 and MYCBP2 downregulate FBXW7 $\alpha$ protein levels during mitotic arrest. a HeLa cells were transfected with $30 \mathrm{nM}$ FBXO45 or FBXW7 siRNAs for $72 \mathrm{~h}$. GL2 siRNA was used as a control. The cells were arrested in mitosis by nocodazole (noco.) treatment for $17 \mathrm{~h}$ and collected by a mitotic shake-off. Mitotic cells were compared with an asynchronous (asy.) cell population. (Top) Cell extracts were analyzed by western blotting. Crossreacting band in FBXO45 immunoblot is marked with an asterisk. As the samples were analyzed in three western blots, three vinculin immunoblots are shown as loading controls. (Bottom) Quantification of relative FBXW7 $\alpha$ and FBXO45 signal intensities are shown. Relative FBXW7 $\alpha$ and
B
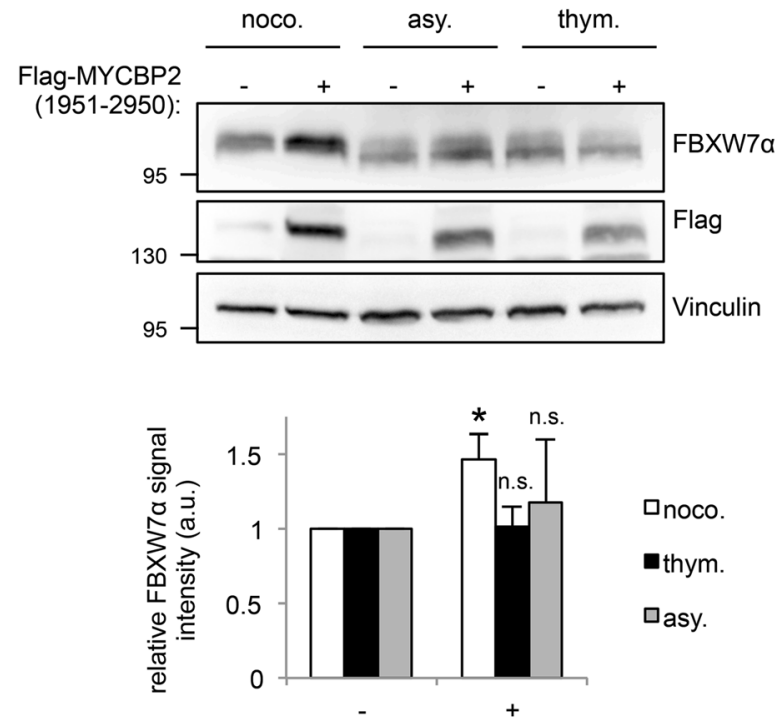

Flag-MYCBP2(1951-2950)

FBXO45 signals in the GL2 controls were set to 1 . Average signal intensities and standard deviations from $n=4$ experiments were calculated. Statistical significance was analyzed by a two-tailed, unpaired $t$-test with unequal variance. ${ }^{*} p<0.05$; n.s. not significant. b Expression of Flag-MYCBP2(1951-2950) was induced in a stable U2OS FlpIn-T-Rex cell line by doxycycline treatment. The cells were arrested in mitosis by nocodazole treatment (noco.). Alternatively, they were treated with thymidine (thym.) or left untreated (asy.). U2OS cells that do not express the MYCBP2 fragment served as controls. (Top) Cell extracts were analyzed by western blotting. (Bottom) Quantification of relative FBXW7 $\alpha$ signal intensity was performed as described in (A) 
A

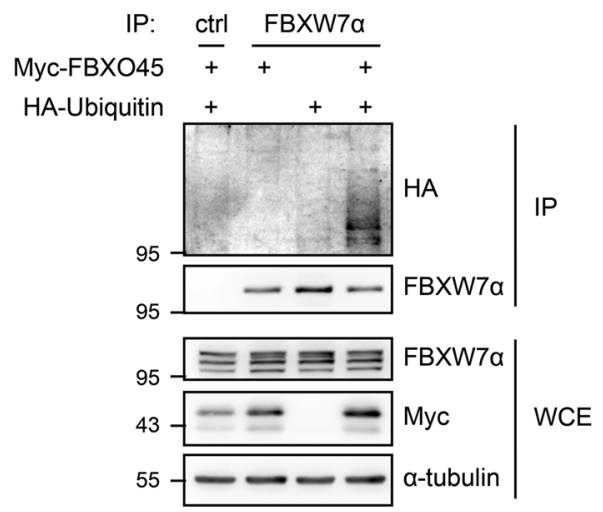

B

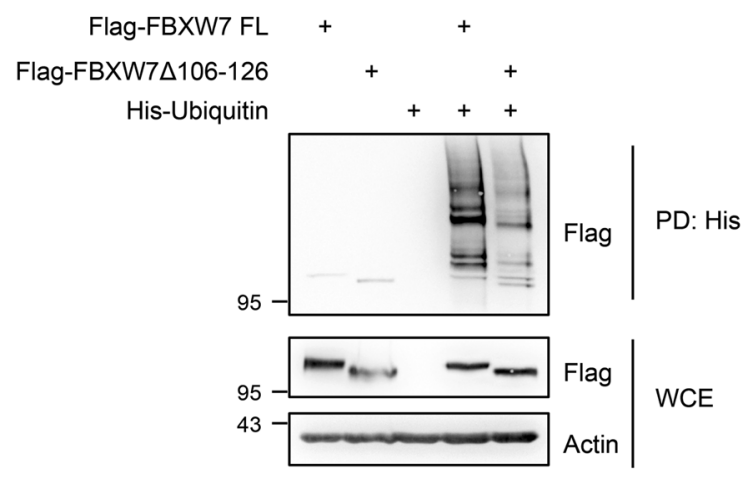

D
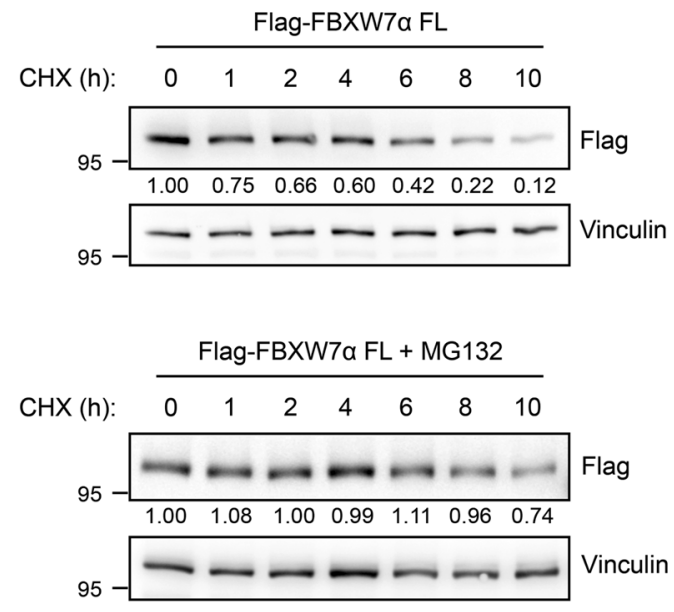

Fig. 5 FBXO45 and MYCBP2 promote the ubiquitylation and destabilization of FBXW7 $\alpha$. a Myc-FBXO45 and HA-Ubiquitin or MycMYCBP2 and Flag-FBXW7 $\alpha$ were overexpressed in HEK-293T cells for $48 \mathrm{~h}$. Cells were arrested in mitosis by nocodazole treatment for 17 h. At $4 \mathrm{~h}$ before harvesting, cells were treated with MG132. Cell extracts were used for immunoprecipitations directed against endogenous FBXW7 $\alpha$ or against the Flag tag. b Flag-FBXW7 $\alpha$ FL or FlagFBXW7 $\alpha \Delta 106-126$ were co-expressed with His-Ubiquitin in HEK293 T cells. The cells were arrested in mitosis by nocodazole treatment. At $4 \mathrm{~h}$ before harvesting, cells were treated with MG132. Cell extracts were prepared and $\alpha$-His pull-downs were performed. c HeLa cells were transfected with $30 \mathrm{nM}$ of GL2 or FBXO45 siRNA for $72 \mathrm{~h}$. At $17 \mathrm{~h}$ before harvesting, the cells were treated with nocodazole. Mitotic

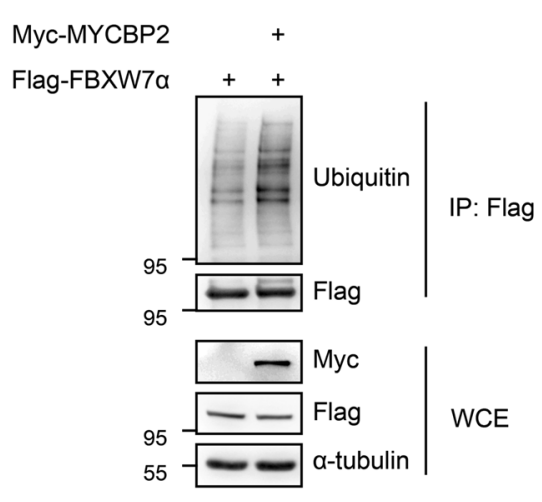

C
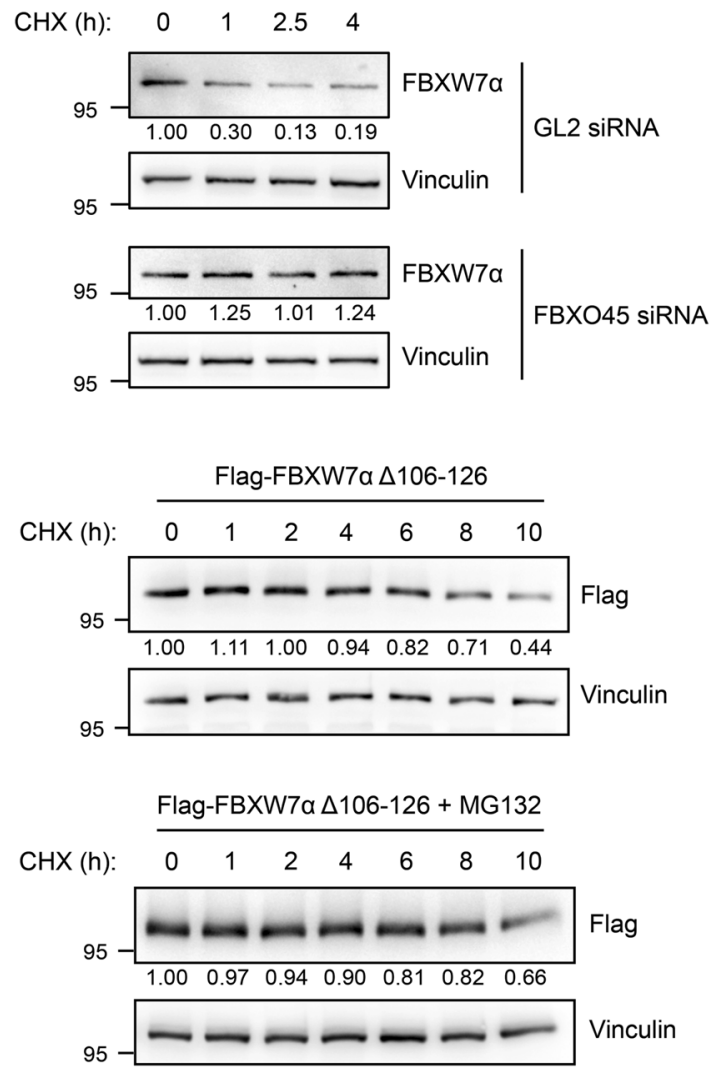

cells were collected by mitotic shake-off and further incubated with nocodazole and cycloheximide ( $\mathrm{CHX}$ ). The cells were harvested at different time points after the addition of cycloheximide by mitotic shake-off. Cell extracts were analyzed by western blotting. Samples were analyzed on a single gel. Relative FBXW7 $\alpha$ signal intensities were quantified. d Flag-FBXW7 $\alpha$ FL or Flag-FBXW7 $\alpha \Delta 106-126$ were overexpressed in U2OS Flp-In-T-Rex cells by treatment with doxycycline. Cells were arrested in mitosis by nocodazole treatment. Cycloheximide (CHX) was added and cells were harvested at different time points after the addition of cycloheximide. MG132 was added in order to inhibit the proteasome. Cell extracts were analyzed by western blotting. Relative Flag signal intensities were quantified 
comparison to full-length Flag-FBXW7 $\alpha$. The stability of Flag-FBXW7 $\alpha$ was increased by MG132 treatment (Fig. 5d). From these experiments, we conclude that FBXO45-MYCBP2 mediated degradation of FBXW7 $\alpha$ during prolonged mitosis depends on the proteasome.

\section{FBX045-MYCBP2 reduces the sensitivity of cells to spindle poisons}

Previous studies have shown that FBXW7 regulates mitotic cell fate. In fact, FBXW7 promotes mitotic cell death and prevents mitotic slippage in cells that have been treated with antimicrotubule drugs to arrest them in mitosis [21, 22], which is in line with its function as a tumor suppressor. As we had found that FBXO45-MYCBP2 regulates FBXW7 $\alpha$ protein levels during mitotic arrest (Fig. 4), we asked whether the FBXO45-MYCBP2 complex as a regulator of FBXW7 would also affect mitotic cell fate. To test this, we analyzed mitotic cell fate by live-cell imaging (Fig. 6a, Supplementary Videos 1 and 2). For our live-cell imaging analysis, we treated the cells with spindle poisons at concentrations that completely prevented cell division and caused either mitotic cell death or mitotic slippage [38]. As shown in Fig. 6b, reduction of FBXO45 led to an increase in mitotic cell death in cells that were arrested in mitosis with nocodazole. Similar effects were observed in cells arrested in mitosis by Taxol or vincristine treatment (Supplementary Fig. 3A, B). To exclude off-target effects we used siRNAs targeting different regions of FBXO45 mRNA (Fig. 6b). In addition, expression of an siRNA-resistant version of Flag-FBXO45 was able to rescue the effect on mitotic cell fate (Fig. 6c). Moreover, siRNA-mediated downregulation of MYCBP2 also caused an increase in mitotic cell death (Supplementary Fig. 3C). In contrast, FBXO45 and MYCBP2 depletion did not have an effect on progression of cells through an unperturbed mitosis (Supplementary Fig. 3D). To verify the results in an siRNA independent approach, we analyzed the effect of the dominant-negative MYCBP2(1951-2950) fragment on mitotic cell fate. As expected, overexpression of FlagMYCBP2(1951-2950) increased mitotic cell death (Fig. 6d). Taken together, our results showed that the FBXO45-MYCBP2 complex negatively regulates mitotic cell death and increases mitotic slippage, suggesting that it has an opposing function during mitotic arrest compared to FBXW7. This is in line with the FBXO45MYCBP2 complex being a negative regulator of FBXW7 $\alpha$ during mitotic arrest. We therefore asked whether the observed effect of FBXO45-MYCBP2 on mitotic cell fate depends on FBXW7. In fact, FBXW7 depletion was able to rescue the effect of FBXO45, suggesting that FBXW7 is the downstream target of the FBXO45MYCBP2 complex that mediates mitotic cell fate regulation (Fig. 6e). Together, our data strongly suggest that FBXO45-MYCBP2-mediated degradation of FBXW7 under prolonged mitotic arrest induces mitotic slippage and prevents mitotic cell death.

\section{Discussion}

The results presented here demonstrate that the FBXO45MYCBP2 complex is a novel E3 ubiquitin ligase regulating the protein levels of FBXW7 $\alpha$ during prolonged mitotic arrest induced by antimicrotubule drugs through ubiquitinmediated degradation. This degradation leads to a reduction of the sensitivity to microtubule-targeting drugs by causing a decrease in mitotic cell death and promoting mitotic slippage.

Prolonged mitotic arrest is caused by a sustained activation of the SAC. If the SAC cannot be satisfied and mitosis cannot be completed, there are two alternative cell fates. Cells either undergo mitotic cell death or perform mitotic slippage. Cell fate following mitotic arrest is regulated by two competing networks, namely Cyclin B1 degradation and proapoptotic caspase activation [39]. Besides cell fate regulation through Cyclin B1, MCL-1, a prosurvival member of the BCL-2 family, was shown to be involved in cell fate decision. MCL-1 is degraded by a ubiquitin-proteasome-dependent mechanism in response to the disruption of mitosis, resulting in cell death [39, 30, 22].

The tumor suppressor FBXW7 also plays important roles in mitotic cell fate decision [22, 29, 21]. However, whether or not FBXW7 has a direct role in regulating MCL-1 levels is a matter of debate $[22,40,29]$ and therefore the identification of the substrate(s) of FBXW7 involved in regulating mitotic cell fate is an important task for future studies.

Our work identifies FBXO45 as a protein binding to a conserved acidic amino acid motif (aa106-126) of FBXW7 $\alpha$ (Figs. 1 and 2) to form a ternary complex with MYCBP2. Interestingly, available TCGA data show that FBXO45 is frequently overexpressed in different cancer types (cBioPortal for Cancer Genomics) [41, 42]. Therefore, it could be meaningful to further characterize $\mathrm{FBXO} 45$ as a putative oncoprotein in future studies. MYCBP2 has been recently uncovered as a novel type of E3 ligase with esterification activity leading to ubiquitylation of serine and threonine residues in substrates [43], which is intrinsic to higher eukaryotes. In the future, it would therefore be interesting to see whether FBXW7 could be ubiquitylated on hydroxyl groups by MYCBP2.

Apart from the regulation of FBXW7 protein levels by GLMN-dependent autoubiquitylation [13, 14], Parkinmediated degradation [15] as well as PLK2-dependent phosphorylation [16], FBXW7 activity can also be regulated by the pseudophosphatase STYX that binds to the 
A

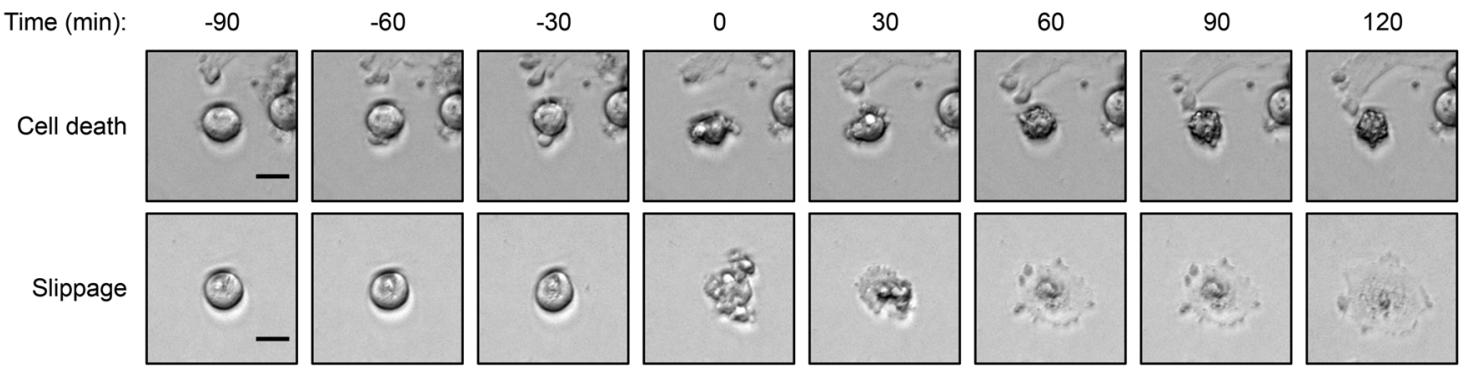

B

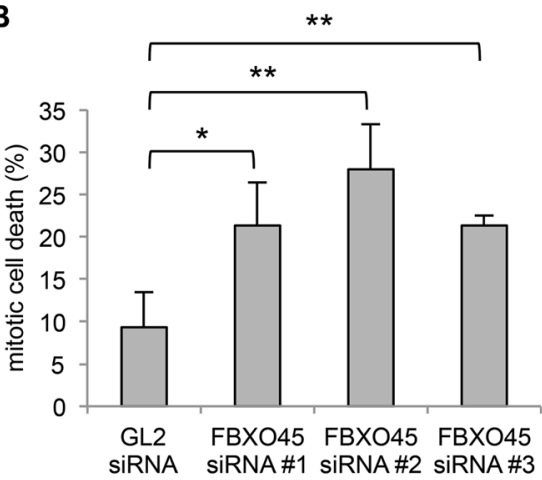

C

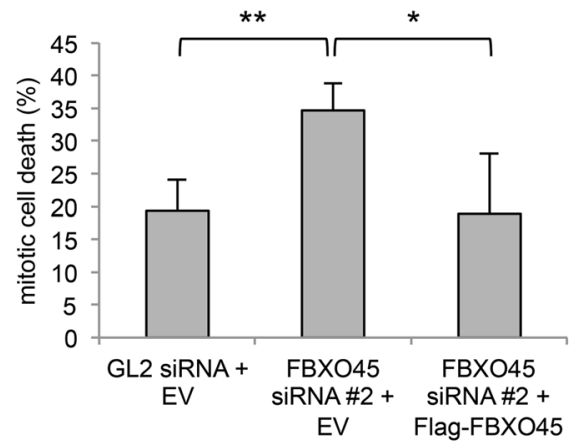

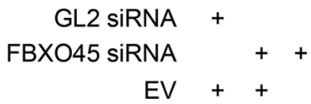

Flag-FBXO45

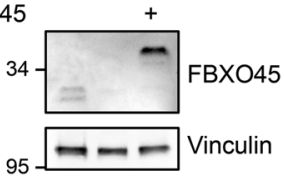

D

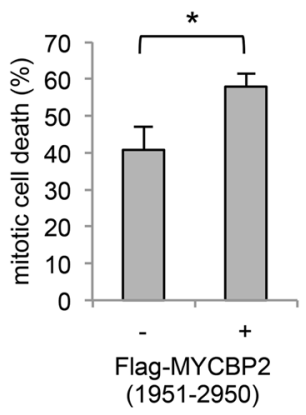

Fig. 6 FBXO45 and MYCBP2 cause mitotic slippage. a U2OS cells were treated with $250 \mathrm{ng} / \mathrm{mL}$ nocodazole. At $4 \mathrm{~h}$ after nocodazole addition, cells were analyzed by live-cell imaging. Representative images from live-cell imaging are shown. Time point 0 marks induction of mitotic cell death or mitotic slippage. Scale bars: $20 \mu \mathrm{m}$. b U2OS cells were transfected with $30 \mathrm{nM}$ of GL2 or different FBXO45 siRNAs for $48 \mathrm{~h}$ and further incubated with $250 \mathrm{ng} / \mathrm{mL}$ nocodazole. Percentages of cells undergoing mitotic cell death were quantified. Cells from $n=3$ independent experiments were analyzed. In each experiment, 50 cells were quantified. c U2OS cells were cotransfected with $40 \mathrm{nM}$ of GL2 or FBXO45 siRNA and an empty vector (EV) or an siRNA-resistant version of Flag-FBXO45. At $48 \mathrm{~h}$ after transfection, the cells were treated with nocodazole and mitotic

F-box domain of FBXW7 and disables its recruitment into the SCF complex [44, 45]. Similar to FBXO45, STYX is also a direct regulator of FBXW7 function.

As FBXW7 $\alpha$ is a nuclear protein but FBXO45 is found in the cytoplasm (Fig. 3a), the two proteins can only interact upon nuclear envelope breakdown (Fig. 3b). However, since mitosis is a relatively short process in the eukaryotic cell fate was analyzed by live-cell imaging. Cells from $n=4$ independent experiments were quantified. d Expression of Flag-MYCBP2 (1951-2950) was induced in U2OS cells by treatment with doxycycline for $48 \mathrm{~h}$. Cells were arrested in mitosis by treatment with nocodazole and mitotic cell fate was analyzed by live-cell imaging. Cells from $n=3$ independent experiments were analyzed. e U2OS cells were transfected with $30 \mathrm{nM}$ of GL2, FBXO45, or FBXW7 siRNA or cotransfected with FBXO45 and FBXW7 siRNA. At $48 \mathrm{~h}$ after transfection, the cells were treated with nocodazole and mitotic cell fate was analyzed by live-cell imaging. Cells from $n=3$ independent experiments were quantified. For statistical analysis in $\mathbf{b}-\mathbf{e}$, significance was analyzed by a two-tailed, unpaired $t$-test. ${ }^{*} p<0.05$, ** $p$ $<0.01$, n.s. not significant

cell cycle, the successful formation of a sustained interaction between FBXO45 and FBXW7 $\alpha$ as well as FBXW7 $\alpha$ ubiquitylation may require a longer arrest in mitosis. Interestingly, the degradation of two other regulators of mitotic cell fate, MCL-1 and Cyclin B1, has also been shown to occur in a slow and gradual manner during mitotic arrest $[18,30]$. 
In the future, the development of a specific inhibitor to block the FBXO45-MYCBP2-FBXW7 $\alpha$ axis might actively promote mitotic cell death and prevent mitotic slippage. A possible new approach for blocking the FBXW7 $\alpha / \mathrm{FBXO} 45$ interaction would be to target the complex with ubiquitin variants (Ubvs). Ubvs have recently been generated by phage display in order to inhibit FBXW7 activity [46]. A similar strategy could be pursued to develop an inhibitor of FBXW7 $\alpha / \mathrm{FBXO} 45$ complex formation. Treatment of cancer patients with this inhibitor after or in combination with antimicrotubule drugs could be a promising approach in order to increase the efficiency of chemotherapeutic treatment.

\section{Materials and methods}

\section{Cell culture and transfection}

Human cell lines were grown in a humidified atmosphere with $5 \% \quad \mathrm{CO}_{2}$ at $37^{\circ} \mathrm{C}$. HeLa (ATCC CCL-2), U2OS (ATCC HTB-96), and U2OS Flp-In-T-Rex (J.D. Parvin, Ohio State University) cells were cultured in Dulbecco's Modified Eagle's Medium (DMEM, Sigma-Aldrich) with 1 g/l glucose. HEK-293T (ACC 635; DSMZ, Braunschweig, Germany) cells were grown in DMEM with $4.5 \mathrm{~g} / 1$ glucose. The media were supplemented with $10 \%$ fetal bovine serum (FBS, Sigma-Aldrich or Thermo Scientific). HeLa GFP- $\alpha$ tubulin/RFP-H2B cells (D. Gerlich, ETH Zürich) were cultured in DMEM containing $1 \mathrm{~g} / \mathrm{l}$ glucose, 10\% FBS, 500 $\mu \mathrm{g} / \mathrm{ml} \mathrm{G} 418$, and $0.5 \mu \mathrm{g} / \mathrm{ml}$ puromycin. The T-Rex system was used to generate U2OS Flp-In-T-Rex Flag-FBXW7 $\alpha$, U2OS Flp-In-T-Rex Flag-FBXW7 $\alpha \Delta 106-126$, and U2OS Flp-In-T-Rex Flag-MYCBP2(1951-2950) stable cell lines according to the manufacturer's instructions (Life Technologies).

Cell culture work was performed under sterile conditions. Cell line authentication was regularly performed by Multiplexion in Heidelberg. Cell lines were regularly tested for mycoplasma contamination.

HEK-293T and HeLa cells were transiently transfected with plasmid DNA using polyethylenimine (PEI, Polysciences) at a final concentration of $5 \mu \mathrm{g} / \mathrm{ml}$. The cells were incubated at $37^{\circ} \mathrm{C}$ and harvested $24-48 \mathrm{~h}$ after transfection. If the cells were harvested $48 \mathrm{~h}$ after transfection, the transfection mixture was removed 6-24 h after transfection and replaced by fresh growth medium.

For the transfection of HeLa or U2OS cells with siRNA, the transfection reagent Lipofectamine 2000 (Invitrogen) was used according to the manufacturer's instructions. Cells were transfected with $30 \mathrm{nM}$ of siRNA for $72 \mathrm{~h}$. For rescue experiments, $50 \mathrm{ng}$ of plasmid was cotransfected with 40 $\mathrm{nM}$ of siRNA for $72 \mathrm{~h}$.

The following siRNA sequences were used:

GL2 (firefly luciferase, control), 5'-CGUACGCG GAAUACUUCGAtt-3';

FBXO45 \#1, 5'-GGAGAAAGAAUUCGAGUCAtt-3'; FBXO45 \#2, 5'-ACACAUGGUUAUUGCGUAUtt-3'; FBXW7, 5'-ACAGGACAGUGUUUACAAAtt-3'; MYCBP2 \#1, 5'-CCCGAGAUCUUGGGAAUAAtt-3'.

FBXO45 \#3 (200933, L-023542-01-0005) and MYCBP2 \#2 (23077, L-006951-00-0005) were purchased as SMARTpools from Dharmacon. If not stated otherwise, FBXO45 siRNA \#2 was used for FBXO45 depletion and MYCBP2 siRNA \#2 was transfected in order to downregulate $\mathrm{MYCBP} 2$.

\section{Plasmids}

Human FBXW7 $\alpha$ and FBXO45 cDNAs were obtained from the Genomics and Proteomics Core Facility at the DKFZ (Heidelberg, Germany). Full-length FBXW7 $\alpha$ and FBXW7 $\alpha$ fragments were cloned into pCMV-3Tag $1 \mathrm{C}$ and pMAL-C2 vectors via EcoRI and HindIII sites. FBXO45 was cloned into pCMV-3Tag1A, pCMV-3Tag2A, and pCDNA3.1-HA vectors via BamHI and XhoI sites. pCDNA3.1-Flag-FBXO45 was a gift from G. Melino (Rome, Italy). 3xFlag-FBXW7 $\beta$-myc-CMV and 3xFlagFBXW7 $\gamma$-myc-CMV were a gift from B.E. Clurman (Seattle, US). pCMV-MYCBP2-FL was received from Addgene (plasmid \#42570). MYCBP2 fragments were cloned into pCMV-3Tag1A vector via SrfI and XhoI sites. pCDNA3.1-Flag-FBXW5 was a gift from F. Melchior (Heidelberg, Germany). pCDNA3.1-Flag-FBXL2 was a gift from L. Hengst (Innsbruck, Austria). pCMV-3Tag1AFBXO28 has been described before [47]. VPRBP (cDNA received from Genomics and Proteomics Core Facility at the DKFZ) was cloned into pCMV-3Tag1C vector via EcoRI and XhoI sites. DCAF5 was cloned into pCMV3Tag1A vector via BamHI and XhoI sites.

\section{Cell cycle synchronization}

In order to arrest HeLa or U2OS cells in G1/S phase, the cells were treated with $2 \mathrm{mM}$ thymidine for $18 \mathrm{~h}$. In order to arrest HeLa or U2OS cells in mitosis, cells were first synchronized in G1/S phase by treatment with $2 \mathrm{mM}$ thymidine for $17 \mathrm{~h}$. The cells were released into the cell cycle by washing three times with PBS and incubation with fresh growth medium for $5 \mathrm{~h}$. Finally, the cells were treated with $250 \mathrm{ng} / \mathrm{ml}$ nocodazole, $500-1000 \mathrm{nM}$ Taxol, $500 \mathrm{nM}$ vincristine, $5 \mu \mathrm{M}$ STLC, or $100 \mathrm{nM} \mathrm{BI2536}$ for $16-17 \mathrm{~h}$. Mitotic cells were collected by a mitotic shake-off. 


\section{MG132 and cycloheximide treatment}

In order to inhibit proteasomal degradation in HEK-293T cells, the cells were treated with $10 \mu \mathrm{M}$ MG132 (SigmaAldrich) for $4-5 \mathrm{~h}$ before harvesting. In order to inhibit protein synthesis in HeLa cells, they were treated with $100 \mu \mathrm{g} / \mathrm{ml}$ cycloheximide (Sigma-Aldrich). For a cycloheximide chase assay, the cells were harvested at different time points after cycloheximide treatment.

\section{Live-cell imaging}

For the analysis of mitotic cell fate or unperturbed mitotic progression, live-cell imaging was performed. For mitotic cell fate analysis, U2OS cells were transfected with $30 \mathrm{nM}$ siRNA targeting GL2, FBXW7, FBXO45, or MYCBP2. At $48 \mathrm{~h}$ after transfection, $2.5 \times 10^{4}$ cells were seeded into Ibidi dish chambers. At $72 \mathrm{~h}$ after transfection, the cells were treated with $250 \mathrm{ng} / \mathrm{ml}$ nocodazole, $1 \mu \mathrm{M}$ Taxol or $500 \mathrm{nM}$ vincristine. At $4 \mathrm{~h}$ after the spindle poison treatment, the cells were monitored by a $10 \times / 0.3$ EC PlnN Ph1 DICI objective on a Zeiss Cell Observer Z1 inverted microscope (AxioCam MRm camera system) with incubation at 5\% $\mathrm{CO}_{2}$ and $37^{\circ} \mathrm{C}$. Multi-tile phase-contrast images were taken every $10 \mathrm{~min}$ for $48 \mathrm{~h}$ using the Zeiss ZEN blue software. Data analysis was performed with ImageJ Fiji software. Cell death was defined by cell morphology and cessation of movement. Mitotic slippage was defined by mitotic exit without cell division. For the analysis of unperturbed mitotic progression, HeLa GFP- $\alpha$-tubulin/RFP-H2B cells were transfected with $30 \mathrm{nM}$ siRNA targeting GL2 or FBXO45 and MYCBP2. Analysis was performed as described previously [47]. At $48 \mathrm{~h}$ after transfection, $2.5 \times$ $10^{4}$ cells were seeded into Ibidi dish chambers and arrested in $\mathrm{G} 1 / \mathrm{S}$ phase by thymidine treatment. At $24 \mathrm{~h}$ after thymidine addition, the cells were released from the arrest and analyzed by live-cell imaging using LED module Colibri.2 with $470 \mathrm{~nm}$ for GFP and $590 \mathrm{~nm}$ for RFP fluorochrome excitation.

\section{Preparation of protein extracts from mammalian cells}

For the preparation of cell extracts, cell pellets were resuspended in 3-5 volumes of RIPA, NP40, or Urea lysis buffer. RIPA lysis buffer $(50 \mathrm{mM}$ Tris- $\mathrm{HCl} \mathrm{pH} 7.4,1 \%$ NP40, $0.5 \%$ Na-deoxycholate, $0.1 \%$ SDS, $150 \mathrm{mM}$ $\mathrm{NaCl}, 2 \mathrm{mM}$ EDTA, $50 \mathrm{mM} \mathrm{NaF}, 1 \mathrm{mM}$ DTT, $10 \mu \mathrm{g} / \mathrm{ml}$ TPCK, $5 \mu \mathrm{g} / \mathrm{ml}$ TLCK, $0.1 \mathrm{mM} \mathrm{Na} \mathrm{VO}_{4}, 1 \mu \mathrm{g} / \mathrm{ml}$ Aprotinin, $1 \mu \mathrm{g} / \mathrm{ml}$ Leupeptin, and $10 \mu \mathrm{g} / \mathrm{ml}$ Trypsin inhibitor from soybean) was used for the analysis of protein levels in whole cell extracts and for in vivo ubiquitylation assays. NP40 lysis buffer (40 mM Tris- $\mathrm{HCl} \mathrm{pH} 7.5,150 \mathrm{mM} \mathrm{NaCl}$,
$5 \mathrm{mM}$ EDTA, $10 \mathrm{mM} \beta$-glycerophosphate, $5 \mathrm{mM} \mathrm{NaF}$, $0.5 \% \mathrm{NP} 40,1 \mathrm{mM}$ DTT, $10 \mu \mathrm{g} / \mathrm{ml}$ TPCK, $5 \mu \mathrm{g} / \mathrm{ml}$ TLCK, $0.1 \mathrm{mM} \mathrm{Na} \mathrm{VO}_{4}, 1 \mu \mathrm{g} / \mathrm{ml}$ Aprotinin, $1 \mu \mathrm{g} / \mathrm{ml}$ Leupeptin, and $10 \mu \mathrm{g} / \mathrm{ml}$ Trypsin inhibitor from soybean) was used for immunoprecipitations. Urea lysis buffer (8 M Urea, $30 \mathrm{mM}$ imidazole, and $0.1 \mathrm{M}$ phosphate buffer $\mathrm{pH}$ 8.0) was used for in vivo ubiquitylation assays. The cell lysates were incubated on ice for $30 \mathrm{~min}$ with short vortexing every 5-10 min. The lysates were cleared by centrifugation at maximal speed and $4{ }^{\circ} \mathrm{C}$ in an Eppendorf $5415 \mathrm{R}$ centrifuge for $15 \mathrm{~min}$. The supernatants were transferred to fresh reaction tubes. Extracts of cytoplasmic and nuclear cell fractions were prepared using the CelLytic NuCLEAR Extraction Kit (Sigma) according to the manufacturer's instructions.

The protein concentration of a cell extract was determined according to the Bradford method in a Bio-Rad Protein assay. For SDS-PAGE, the cell extracts were mixed with equal volumes of $2 \times$ Laemmli buffer and incubated at $95{ }^{\circ} \mathrm{C}$ for $5 \mathrm{~min}$.

\section{Western blotting}

The following antibodies were used for western blotting: rabbit $\alpha$-FBXW7 $\alpha$ antibody (A301-720A, 1:15,000) was obtained from Bethyl. Rabbit $\alpha$-FBXO45 (NBP1-91891, 1:500) was purchased from Novus. Rabbit $\alpha-\mathrm{MYCBP} 2$ was a kind gift from K. Scholich [48]. Mouse $\alpha$-Flag (M2, F3165, 1:5000), mouse $\alpha$-tubulin (B-5-1-2, 1:10,000), and mouse $\alpha$-Vinculin (hVIN-1, 1:5000) were obtained from Sigma-Aldrich. Rabbit $\alpha$-Cyclin B1 has been described before [49]. Mouse $\alpha$-HA (16B12, 1:1000) was purchased from Babco. Mouse $\alpha$-Myc (9E10, 1:500), rabbit $\alpha$-SKP1 (H-163, 1:1000), and mouse $\alpha$-ubiquitin (P4D1, 1:1000) were obtained from Santa Cruz. Mouse $\alpha$-Nucleophosmin (NPM, 32-5200, 1:1000) was ordered from Zymed. Rabbit $\alpha$-MCL-1 (4572, 1:1000) was obtained from cell signaling. Goat $\alpha$-mouse IgG HRP (1:5000) was purchased from Novus. Donkey $\alpha$-rabbit IgG HRP (1:5000) was obtained from Jackson Laboratories.

\section{Immunoprecipitation}

Immunoprecipitations of Flag-tagged proteins were performed using $\alpha$-Flag M2 affinity beads (Sigma-Aldrich). For each immunoprecipitation reaction, $10-40 \mu \mathrm{l}$ of the $\alpha$ Flag M2 affinity bead suspension was used. The beads were washed twice with TBS, once with glycine buffer $(0.1 \mathrm{M}$ glycine-HCl pH 3.5) and three times with TBS. Buffers and beads were kept on ice and centrifugations were performed at $5000 \mathrm{rpm}$ and $4{ }^{\circ} \mathrm{C}$ for $2 \mathrm{~min}$ in an Eppendorf $5415 \mathrm{R}$ centrifuge. HEK-293T or HeLa cell extracts were prepared with NP40 lysis buffer and 6-15 mg of each extract was 
transferred to the prepared beads. Each reaction was filled up to a final volume of $1 \mathrm{ml}$ using NP40 lysis buffer. The reactions were incubated overnight on a rotating wheel at $4{ }^{\circ} \mathrm{C}$. After the incubation, the beads were washed 3-5 times with NP40 lysis buffer. Immunoprecipitated proteins were eluted from the beads by competition with $100 \mu$ of a $3 \times$ Flag peptide solution (100-500 ng/ $\mu \mathrm{l}$ in NP40 lysis buffer). The elution was carried out on ice for $30 \mathrm{~min}$ with short vortexing every 5-10 $\mathrm{min}$. After the elution, the beads were centrifuged at $5000 \mathrm{rpm}$ and $4{ }^{\circ} \mathrm{C}$ for $2 \mathrm{~min}$. Ninety microliters of the supernatant were transferred to a fresh reaction tube and $30 \mu \mathrm{l}$ of $4 \times$ Laemmli buffer were added. After incubation at $95^{\circ} \mathrm{C}$ for $2 \mathrm{~min}, 20-40 \%$ of the immunoprecipitation sample was analyzed by SDS-PAGE and western blotting.

In order to analyze whether proteins exist in ternary complexes, sequential immunoprecipitations were performed. In the first step of the experiment, $15-20 \mathrm{mg}$ of HEK-293T cell extracts were used for an immunoprecipitation directed against a Flag-tagged MYCBP2 fragment. The immunoprecipitation was performed as described above. Instead of mixing the eluate with Laemmli buffer, it was used for a second immunoprecipitation directed against HA-FBXO45. HA-FBXO45 was immunoprecipitated with $20 \mu \mathrm{l}$ of $\alpha$-HA agarose beads (Sigma-Aldrich) according to the manufacturer's instructions. Finally, the beads were incubated with $30 \mu \mathrm{l}$ of $2 \times$ Laemmli buffer at $95^{\circ} \mathrm{C}$ for $5 \mathrm{~min}$. The supernatant was analyzed by SDS-PAGE and western blotting.

\section{Mass spectrometry analysis}

Immunoprecipitation samples were analyzed by SDSPAGE and stained by Colloidal Coomassie. Analysis was performed by M. Schnölzer (DKFZ Protein Analysis Facility, Heidelberg). Briefly, whole gel lanes were cut into slices. Proteins were reduced and alkylated by incubation with $10 \mathrm{mM}$ DTT in $40 \mathrm{mM} \mathrm{NH} \mathrm{HCO}_{3}$ for $1 \mathrm{~h}$ at $56^{\circ} \mathrm{C}$ in the dark and incubation with $55 \mathrm{mM}$ iodoacetamide in $40 \mathrm{mM} \mathrm{NH}_{4} \mathrm{HCO}_{3}$ for $30 \mathrm{~min}$ at $25^{\circ} \mathrm{C}$. After washing of the slices with $\mathrm{H}_{2} \mathrm{O}$ and $50 \%$ acetonitrile, they were dried with $100 \%$ acetonitrile. Proteins were digested in-gel with trypsin $\left(0.17 \mu \mathrm{g}\right.$ in $10 \mu \mathrm{l} 40 \mathrm{mM} \mathrm{NH} \mathrm{HCO}_{3}$, Promega $)$ at $37^{\circ} \mathrm{C}$ overnight. Tryptic peptides were extracted with $50 \%$ acetonitrile $/ 0.1 \%$ TFA and $100 \%$ acetonitrile. Supernatants were lyophilized and redissolved in $0.1 \% \mathrm{TFA} / 5 \%$ hexafluoroisopropanol. Solutions were analyzed by nanoLCESI-MS/MS. Peptides were separated with a nanoAcquity UPLC system (Waters $\mathrm{GmbH}$ ). Peptides were loaded on a C18 trap column with a particle size of $5 \mu \mathrm{m}$ (Waters $\mathrm{GmbH})$. Liquid chromatography was carried out on a BEH130 C18 column with a particle size of $1.7 \mu \mathrm{m}$ (Waters $\mathrm{GmbH})$. A $1 \mathrm{~h}$ gradient was applied for protein identification. The nanoUPLC system was connected to an LTQ Orbitrap XL mass spectrometer (Thermo Scientific). Data were acquired with the Xcalibur software 2.1 (Thermo Scientific). The SwissProt database (taxonomy human) was used for database searches with the MASCOT search engine (Matrix Science). Data from individual gel slices were merged. Peptide mass tolerance was $5 \mathrm{ppm}$, fragment mass tolerance was $0.4 \mathrm{Da}$ and significance threshold was $p<0.01$.

\section{In vivo ubiquitylation assays}

HEK-293T cells transiently transfected with the indicated plasmids were treated with $10 \mu \mathrm{M}$ MG132 $4-5 \mathrm{~h}$ before harvesting. Cells were harvested and cell extracts were prepared with RIPA lysis buffer containing $10 \mathrm{mM}$ of the DUB inhibitor N-ethylmaleimide (NEM). In all, $2-3 \mathrm{mg}$ of protein extract was used for each sample. Flag-FBXW7 $\alpha$ was immunoprecipitated with $\alpha$-Flag affinity beads. Immunoprecipitation and washing steps were performed with RIPA lysis buffer containing $10 \mathrm{mM}$ NEM. Alternatively, endogenous FBXW7 $\alpha$ was immunoprecipitated by incubation of each protein extract with $1 \mu \mathrm{g}$ of FBXW7 $\alpha$ antibody on a rotating wheel at $4{ }^{\circ} \mathrm{C}$ overnight. After the incubation with the antibody, the extracts were incubated with $15 \mu$ of protein A sepharose beads (GE Healthcare) on a rotating wheel at $4{ }^{\circ} \mathrm{C}$ for $1 \mathrm{~h}$. The beads were washed four times with RIPA lysis buffer containing $10 \mathrm{mM}$ NEM. Finally, the beads were incubated in $30 \mu \mathrm{l}$ of $2 \times$ Laemmli buffer at $95^{\circ} \mathrm{C}$ for $5 \mathrm{~min}$. Twenty-five microliters of the supernatant were analyzed by SDS-PAGE and western blotting.

For denaturing ubiquitylation assays, cell extracts were prepared using urea lysis buffer. Cell extracts were sonified, centrifuged, and incubated with Nickel-NTA agarose beads on a rotating wheel at RT for $2 \mathrm{~h}$. Afterwards, the beads were washed four times with urea lysis buffer and proteins were finally eluted using $30 \mu \mathrm{l}$ of $2 \times$ Laemmli buffer containing $200 \mathrm{mM}$ imidazole. Twenty-five microliters of the supernatant was analyzed by SDS-PAGE and western blotting.

\section{Expression and purification of MBP-tagged proteins}

Chemically competent Escherichia coli Rosetta (DE3) were transformed with pMAL-MBP-FBXW7 $\alpha-N 167$. A single colony was used to inoculate $10 \mathrm{ml}$ of LB medium containing $100 \mu \mathrm{g} / \mathrm{ml}$ ampicillin and $0.2 \%$ glucose. The culture was incubated overnight at $30^{\circ} \mathrm{C}$ with constant shaking at $180 \mathrm{rpm}$. The overnight culture was used to inoculate 11 of LB medium containing $100 \mu \mathrm{g} / \mathrm{ml}$ ampicillin and $0.2 \%$ glucose. The culture was incubated at $37^{\circ} \mathrm{C}$ with constant shaking at $180 \mathrm{rpm}$. When an $\mathrm{OD}_{600}$ of 0.5 was reached, the 
culture was cooled down on ice at $4{ }^{\circ} \mathrm{C}$ and protein expression was induced by the addition of $0.4 \mathrm{mM}$ isopropyl- $\beta$-D-thiogalactopyranoside. The culture was further incubated overnight at $18{ }^{\circ} \mathrm{C}$ with constant shaking at $180 \mathrm{rpm}$. Bacteria were harvested by centrifugation at 5000 rpm and $4{ }^{\circ} \mathrm{C}$ for $15 \mathrm{~min}(\mathrm{~F} 10-6 \times 500 \mathrm{Y}$ rotor, Piramoon). The pellet was resuspended in $25 \mathrm{ml}$ of cold column buffer. Cell lysis was performed with a high pressure homogenizer (15,000-17,000 psi/1030-1170 bar for one pass, EmulsiFlex C5, Avestin). The lysate was centrifuged at $20,000 \mathrm{~g}$ and $4{ }^{\circ} \mathrm{C}$ for $20 \mathrm{~min}$ (WX Ultra 80, Thermo Scientific). The supernatant was applied onto a column with $1 \mathrm{ml}$ of equilibrated amylose resin (NEB). The column with the beads and the extract was incubated on a rotating wheel at $4{ }^{\circ} \mathrm{C}$ for $1 \mathrm{~h}$. Afterwards, the beads were washed three times with $15 \mathrm{ml}$ of column buffer. Finally, the proteins bound to the beads were eluted with $5 \mathrm{ml}$ of column buffer containing $10 \mathrm{mM}$ maltose. Ten fractions of $500 \mu \mathrm{l}$ each were collected. Protein containing fractions were identified by spotting the fractions on nitrocellulose and staining with Ponceau S solution. Protein containing fractions were pooled and MBP-FBXW7 $\alpha-N 167$ was further purified with a preparative Superdex 200 column in $50 \mathrm{mM}$ Tris- $\mathrm{HCl} \mathrm{pH}$ $8.0,100 \mathrm{mM} \mathrm{NaCl}, 5 \mathrm{mM} \beta$-mercaptoethanol, and $5 \%$ glycerol. Purified MBP-FBXW7 $\alpha-N 167$ fractions were analyzed by SDS-PAGE and Colloidal Coomassie staining. Protein containing fractions were aliquoted, frozen in liquid nitrogen, and stored at $-80^{\circ} \mathrm{C}$.

\section{In vitro transcription and translation and in vitro binding assays}

For in vitro binding assays, FBXO45 and MYCBP2 (1951-2950) cDNA sequences in pCMV-3Tag1A backbones were transcribed and translated in vitro using the TNT T3 coupled reticulocyte system (Promega) according to the manufacturer's instructions. The proteins were synthesized in the presence of $20 \mu \mathrm{Ci}\left[{ }^{35} \mathrm{~S}\right]$-methionine so that synthesized proteins were radioactively labeled. Twenty microliters of the in vitro translated proteins was incubated with $10 \mu \mathrm{g}$ of MBP-FBXW7 $\alpha-\mathrm{N} 167$ or MBP alone coupled to $10 \mu \mathrm{l}$ of amylose beads in a final volume of $500 \mu \mathrm{l}$ NP40 lysis buffer on a rotating wheel at $4{ }^{\circ} \mathrm{C}$ for $2 \mathrm{~h}$. The beads were washed five times with $800 \mu \mathrm{l}$ of NP40 lysis buffer. Finally, the beads were incubated with $30 \mu \mathrm{l}$ of $2 \times$ Laemmli buffer at $95{ }^{\circ} \mathrm{C}$ for $5 \mathrm{~min}$. Input and pulldown samples were analyzed by SDS-PAGE and stained with Colloidal Coomassie. The gel was then incubated with Amersham Amplify Fluorographic reagent (GE Healthcare) for $30 \mathrm{~min}$ with gentle shaking. Afterwards, the gel was dried at $80^{\circ} \mathrm{C}$ for $1 \mathrm{~h}$ in a vacuum dryer and analyzed by autoradiography.

\section{FACS analysis}

For the analysis of mitotic arrest, the cellular DNA content was measured by FACS analysis. Cells were fixed with $70 \%$ ethanol at $-20{ }^{\circ} \mathrm{C}$ and rehydrated in PBS for $15 \mathrm{~min}$ at RT. Afterwards, the cells were resuspended in $300 \mu \mathrm{l}$ of PI staining solution $(30 \mu \mathrm{g} / \mathrm{ml}$ propidium iodide and $10 \mu \mathrm{g} / \mathrm{ml}$ RNase A in PBS) and incubated for $15 \mathrm{~min}$ at RT. Stained cells were analyzed on a FACSCalibur (BD).

\section{Statistical analysis}

For data analysis, Microsoft Excel (for Mac 2011, Version 14.7.3) was used. Quantifications are presented as mean values \pm s.d. Statistical significance was analyzed by twotailed, unpaired Student's $t$ tests. $P$ values $p<0.05$ were regarded as significant $\left({ }^{*} p<0.05 ; \quad * * p<0.01\right)$. More detailed information about experimental statistics (such as sample size, description of sample collection, and the number of replicates) is indicated in the corresponding figure legends. No statistical method was used to predetermine sample size.

Acknowledgements We thank B.E. Clurman, D. Gerlich, L. Hengst, F. Melchior, G. Melino, J.D. Parvin, A. Peschiaroli, and K. Scholich for providing reagents and cell lines. We acknowledge the DKFZ Mass Spectrometry and Microscopy Core Facilities for providing equipment and excellent technical assistance. We thank Bettina Dörr for expert technical assistance. We acknowledge the members of our lab for critically reading the manuscript.

Author contribution IH and KTR designed the experiments. KTR, YTK, and BV performed the experiments. IH and KTR wrote the paper.

\section{Compliance with ethical standards}

Conflict of interest The authors declare that they have no conflict of interest.

Publisher's note: Springer Nature remains neutral with regard to jurisdictional claims in published maps and institutional affiliations.

\section{References}

1. Hershko A, Ciechanover A. The ubiquitin system. Annu Rev Biochem. 1998;67:425-79.

2. Davis RJ, Welcker M, Clurman BE. Tumor suppression by the Fbw7 ubiquitin ligase: mechanisms and opportunities. Cancer Cell. 2014;26:455-64.

3. Nateri AS, Riera-Sans L, Da Costa C, Behrens A. The ubiquitin ligase SCFFbw7 antagonizes apoptotic JNK signaling. Science. 2004;303:1374-8.

4. Wei W, Jin J, Schlisio S, Harper JW, Kaelin WG Jr. The v-Jun point mutation allows c-Jun to escape GSK3-dependent recognition and destruction by the Fbw7 ubiquitin ligase. Cancer Cell. $2005 ; 8: 25-33$. 
5. Welcker M, Orian A, Jin J, Grim JE, Harper JW, Eisenman RN, et al. The Fbw7 tumor suppressor regulates glycogen synthase kinase 3 phosphorylation-dependent c-Myc protein degradation. Proc Natl Acad Sci USA. 2004;101:9085-90.

6. Yada M, Hatakeyama S, Kamura T, Nishiyama M, Tsunematsu R, Imaki $\mathrm{H}$, et al. Phosphorylation-dependent degradation of c-Myc is mediated by the F-box protein Fbw7. EMBO J. 2004;23:2116-25.

7. Koepp DM, Schaefer LK, Ye X, Keyomarsi K, Chu C, Harper JW, et al. Phosphorylation-dependent ubiquitination of cyclin E by the SCFFbw7 ubiquitin ligase. Science. 2001;294:173-7.

8. Moberg KH, Bell DW, Wahrer DC, Haber DA, Hariharan IK. Archipelago regulates Cyclin E levels in Drosophila and is mutated in human cancer cell lines. Nature. 2001;413:311-6.

9. Strohmaier H, Spruck CH, Kaiser P, Won KA, Sangfelt O, Reed SI. Human F-box protein hCdc4 targets cyclin $\mathrm{E}$ for proteolysis and is mutated in a breast cancer cell line. Nature. 2001;413:316-22.

10. Hubbard EJ, Wu G, Kitajewski J, Greenwald I. sel-10, a negative regulator of lin-12 activity in Caenorhabditis elegans, encodes a member of the CDC4 family of proteins. Genes Dev. 1997;11:3182-93.

11. Gupta-Rossi N, Le Bail O, Gonen H, Brou C, Logeat F, Six E, et al. Functional interaction between SEL-10, an F-box protein, and the nuclear form of activated Notch1 receptor. J Biol Chem. 2001;276:34371-8.

12. Galan JM, Peter M. Ubiquitin-dependent degradation of multiple F-box proteins by an autocatalytic mechanism. Proc Natl Acad Sci USA. 1999;96:9124-9.

13. Duda DM, Olszewski JL, Tron AE, Hammel M, Lambert LJ, Waddell MB, et al. Structure of a glomulin-RBX1-CUL1 complex: inhibition of a RING E3 ligase through masking of its E2binding surface. Mol Cell. 2012;47:371-82.

14. Tron AE, Arai T, Duda DM, Kuwabara H, Olszewski JL, Fujiwara Y, et al. The glomuvenous malformation protein Glomulin binds Rbx 1 and regulates cullin RING ligase-mediated turnover of Fbw7. Mol Cell. 2012;46:67-78.

15. Ekholm-Reed S, Goldberg MS, Schlossmacher MG, Reed SI. Parkin-dependent degradation of the F-box protein Fbw7beta promotes neuronal survival in response to oxidative stress by stabilizing Mcl-1. Mol Cell Biol. 2013;33:3627-43.

16. Cizmecioglu O, Krause A, Bahtz R, Ehret L, Malek N, Hoffmann I. Plk2 regulates centriole duplication through phosphorylationmediated degradation of Fbxw7 (human Cdc4). J Cell Sci. 2012;125(Pt 4):981-92.

17. Rieder CL, Maiato H. Stuck in division or passing through: what happens when cells cannot satisfy the spindle assembly checkpoint. Dev Cell. 2004;7:637-51.

18. Brito DA, Rieder CL. Mitotic checkpoint slippage in humans occurs via cyclin $\mathrm{B}$ destruction in the presence of an active checkpoint. Curr Biol. 2006;16:1194-1200.

19. Frederiks CN, Lam SW, Guchelaar HJ, Boven E. Genetic polymorphisms and paclitaxel- or docetaxel-induced toxicities: a systematic review. Cancer Treat Rev. 2015;41:935-50.

20. Haschka M, Karbon G, Fava LL, Villunger A. Perturbing mitosis for anti-cancer therapy: is cell death the only answer? EMBO Rep. 2018;19:e45440.

21. Finkin S, Aylon Y, Anzi S, Oren M, Shaulian E. Fbw7 regulates the activity of endoreduplication mediators and the p53 pathway to prevent drug-induced polyploidy. Oncogene. 2008;27:4411-21.

22. Wertz IE, Kusam S, Lam C, Okamoto T, Sandoval W, Anderson DJ, et al. Sensitivity to antitubulin chemotherapeutics is regulated by MCL1 and FBW7. Nature. 2011;471:110-4.

23. Grill B, Murphey RK, Borgen MA. The PHR proteins: intracellular signaling hubs in neuronal development and axon degeneration. Neural Dev. 2016;11:8.
24. Po MD, Hwang C, Zhen M. PHRs: bridging axon guidance, outgrowth and synapse development. Curr Opin Neurobiol. 2010;20:100-7.

25. Chen X, Sahasrabuddhe AA, Szankasi P, Chung F, Basrur V, Rangnekar VM, et al. Fbxo45-mediated degradation of the tumorsuppressor Par-4 regulates cancer cell survival. Cell Death Differ. 2014;21:1535-45.

26. Kugler JM, Woo JS, Oh BH, Lasko P. Regulation of Drosophila vasa in vivo through paralogous cullin-RING E3 ligase specificity receptors. Mol Cell Biol. 2010;30:1769-82.

27. Nakata K, Abrams B, Grill B, Goncharov A, Huang X, Chisholm $\mathrm{AD}$, et al. Regulation of a DLK-1 and $\mathrm{p} 38$ MAP kinase pathway by the ubiquitin ligase RPM-1 is required for presynaptic development. Cell. 2005;120:407-20.

28. Xiong X, Hao Y, Sun K, Li J, Li X, Mishra B, et al. The Highwire ubiquitin ligase promotes axonal degeneration by tuning levels of Nmnat protein. PLoS Biol. 2012;10:e1001440.

29. Allan LA, Skowyra A, Rogers KI, Zeller D, Clarke PR. Atypical APC/C-dependent degradation of Mcl-1 provides an apoptotic timer during mitotic arrest. EMBO J. 2018;37:e96831.

30. Harley ME, Allan LA, Sanderson HS, Clarke PR. Phosphorylation of Mcl-1 by CDK1-cyclin B1 initiates its Cdc20-dependent destruction during mitotic arrest. EMBO J. 2010;29:2407-20.

31. Kourtis N, Moubarak RS, Aranda-Orgilles B, Lui K, Aydin IT, Trimarchi T, et al. FBXW7 modulates cellular stress response and metastatic potential through HSF1 post-translational modification. Nat Cell Biol. 2015;17:322-32.

32. Huttlin EL, Bruckner RJ, Paulo JA, Cannon JR, Ting L, Baltier K, et al. Architecture of the human interactome defines protein communities and disease networks. Nature. 2017;545:505-9.

33. Liao EH, Hung W, Abrams B, Zhen M. An SCF-like ubiquitin ligase complex that controls presynaptic differentiation. Nature. 2004;430:345-50

34. Welcker M, Clurman BE. FBW7 ubiquitin ligase: a tumour suppressor at the crossroads of cell division, growth and differentiation. Nat Rev Cancer. 2008;8:83-93.

35. Skaar JR, Pagan JK, Pagano M. Mechanisms and function of substrate recruitment by F-box proteins. Nat Rev Mol Cell Biol. 2013;14:369-81.

36. Kimura T, Gotoh M, Nakamura Y, Arakawa H. hCDC4b, a regulator of cyclin $\mathrm{E}$, as a direct transcriptional target of $\mathrm{p} 53$. Cancer Sci. 2003;94:431-6.

37. Pierre SC, Hausler J, Birod K, Geisslinger G, Scholich K. PAM mediates sustained inhibition of cAMP signaling by sphingosine1-phosphate. EMBO J. 2004;23:3031-40.

38. Brito DA, Yang Z, Rieder CL. Microtubules do not promote mitotic slippage when the spindle assembly checkpoint cannot be satisfied. J Cell Biol. 2008;182:623-9.

39. Gascoigne KE, Taylor SS. Cancer cells display profound intraand interline variation following prolonged exposure to antimitotic drugs. Cancer Cell. 2008;14:111-22.

40. Sloss O, Topham C, Diez M, Taylor S. Mcl-1 dynamics influence mitotic slippage and death in mitosis. Oncotarget. 2016;7: 5176-92.

41. Cerami E, Gao J, Dogrusoz U, Gross BE, Sumer SO, Aksoy BA, et al. The cBio cancer genomics portal: an open platform for exploring multidimensional cancer genomics data. Cancer Discov. 2012;2:401-4.

42. Gao J, Aksoy BA, Dogrusoz U, Dresdner G, Gross B, Sumer SO, et al. Integrative analysis of complex cancer genomics and clinical profiles using the cBioPortal. Sci Signal. 2013;6:pl1.

43. Pao KC, Wood NT, Knebel A, Rafie K, Stanley M, Mabbitt PD, et al. Activity-based E3 ligase profiling uncovers an E3 ligase with esterification activity. Nature. 2018;556:381-5.

44. Reiterer V, Figueras-Puig C, Le Guerroue F, Confalonieri S, Vecchi M, Jalapothu D, et al. The pseudophosphatase STYX 
targets the F-box of FBXW7 and inhibits SCFFBXW7 function. EMBO J. 2017;36:260-73.

45. He D, Ma Z, Fang C, Ding J, Yang W, Chen P, et al. Pseudophosphatase STYX promotes tumor growth and metastasis by inhibiting FBXW7 function in colorectal cancer. Cancer Lett. 2019;454:53-65.

46. Gorelik M, Orlicky S, Sartori MA, Tang X, Marcon E, Kurinov $\mathrm{I}$, et al. Inhibition of SCF ubiquitin ligases by engineered ubiquitin variants that target the Cull binding site on the Skp1-F-box interface. Proc Natl Acad Sci USA. 2016;113: 3527-32.
47. Kratz AS, Richter KT, Schlosser YT, Schmitt M, Shumilov A, Delecluse HJ, et al. Fbxo28 promotes mitotic progression and regulates topoisomerase IIalpha-dependent DNA decatenation. Cell Cycle. 2016;15:3419-31.

48. Dorr A, Pierre S, Zhang DD, Henke M, Holland S, Scholich K. MYCBP2 is a guanosine exchange factor for ran protein and determines its localization in neurons of dorsal root ganglia. J Biol Chem. 2015;290:25620-35.

49. Hoffmann I, Draetta G, Karsenti E. Activation of the phosphatase activity of human cdc25A by a cdk2-cyclin E dependent phosphorylation at the G1/S transition. EMBO J. 1994;13:4302-10. 